\title{
An integrated dual functional recognition/amplification bio-label for the one- step impedimetric detection of Micro-RNA-21
}

Sawsen Azzouzi, Wing Cheung Mak, Kamalodin Kor, Anthony Turner, Mounir Ben Ali and Valerio Beni

Journal Article

\section{Tweet}

N.B.: When citing this work, cite the original article.

Original Publication:

Sawsen Azzouzi, Wing Cheung Mak, Kamalodin Kor, Anthony Turner, Mounir Ben Ali and Valerio Beni, An integrated dual functional recognition/amplification bio-label for the one-step impedimetric detection of Micro-RNA-21, Biosensors \& bioelectronics, 2017. 92, pp.154-161. http://dx.doi.org/10.1016/j.bios.2017.02.014

Copyright: Elsevier

http://www.elsevier.com/

Postprint available at: Linköping University Electronic Press

http://urn.kb.se/resolve?urn=urn:nbn:se:liu:diva-136850

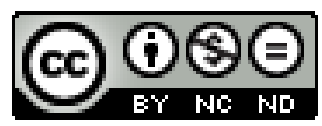




\title{
1 An integrated dual functional recognition/amplification bio-label 2 for the one-step impedimetric detection of Micro-RNA-21.
}

3

Sawsen Azzouzi ${ }^{\mathrm{a}, \mathrm{b}}$, Wing Cheung Mak ${ }^{\mathrm{a},}$, Kamalodin Kor $^{\mathrm{a}, \mathrm{c}}$, Anthony P.F. Turner ${ }^{\mathrm{a}}$, Mounir Ben Ali ${ }^{\mathrm{b}}$, Valerio Beni ${ }^{\mathrm{a}, \text {,\# }}$

${ }^{a}$ Biosensors and Bioelectronics Centre, Department of Physics, Chemistry and Biology (IFM), Linköping University, S-58183 Linköping, Sweden

${ }^{b}$ University of Sousse, Higher Institute of Applied Sciences and Technology of Sousse, GREENS-ISSAT, Cité Ettafala, 4003 Ibn Khaldoun Sousse, Tunisia

${ }^{c}$ Iranian National Institute for Oceanography and Atmospheric Science (INIOAS), P.O. Box 14155-4781, Tehran, Iran.

${ }^{*}$ Corresponding authors:

Dr. Valerio Beni; Dr. Wing Cheung Mak

e-mail:valerio.beni@acreo.se; wing.cheung.mak@liu.se

\# Current affiliation:

ACREO SWEDISH ICT AB, SE-601 17 Norrköping, Sweden

\begin{abstract}
Alteration in expression of miRNAs has been correlated with different cancer types, tumour stage and response to treatments. In this context, a structurally responsive oligonucleotidebased electrochemical impedimetric biosensor has been developed for the simple and sensitive detection of miRNA-21. A highly specific biotinylated DNA/LNA molecular beacon (MB) probe was conjugated with gold nanoparticles (AuNPs) to create an integrated, dual function bio-label (biotin-MB-AuNPs) for both biorecognition and signal generation. In the presence of target miRNA-21, hybridization takes place resulting in the "activation" of the biotin-MB; this event makes the biotin group, which was previously "protected" by the steric hindrance of the MB stem-loop structure, accessible. The activated biotin-MBAuNPs/miRNA complexes become available for capture, via supramolecular interaction, onto
\end{abstract}


a nentravidin-modified electrode for electrochemical transduction. The binding event results in a decrease of the charge transfer resistance at the working electrode/electrolyte interface. The biosensor responded linearly in the range 1 to $1000 \mathrm{pM}$ of miRNA-21, with a limit of detection of $0.3 \mathrm{pM}$, good reproducibility (Relative Standard deviation $(\mathrm{RSD})=3.3 \%$ ) and high selectivity over other miRNAs (i.e. miRNA-221 and miRNA-205) sequences. Detection of miRNA-21 in spiked serum samples at clinically relevant levels (low pM range) was also demonstrated, thus illustrating the potential of the biosensor for point-of-care clinical applications. The proposed biosensor design, based on the combination of a neutravidin transducing surface and the dual-function biotin-MB-AuNPs bio-label, provides a simple and robust approach for detection of short-length nucleic acid targets, such as miRNAs.

Keywords: MicroRNA-21; Gold nanoparticles; Molecular beacon; Electrochemical impedance spectroscopy.

\section{Introduction}

MicroRNAs (miRNAs) are short, single-stranded non-coding RNA molecules, containing between 17 and 25 nucleotides, that play a significant role in several biological processes including: cell proliferation, developmental regulation, differentiation and epigenetic inheritance (Wienholds et al., 2005; Johnson et al., 2007). Recent studies have shown that the alteration in expression levels of miRNAs in body fluid can be correlated to cancer type, tumour stage and/or response to treatments (Croce, 2009). Among the more than 1,200 identified miRNAs (Liu et al., 2012), miRNA-21 has been found to be commonly over expressed in the presence of solid tumours of the lung, breast, stomach, prostate, colon, brain, head and neck, esophagus and pancreas (Lu et al., 2008). This correlation has significantly increased interest in miRNA-21 as a new biomarker for early stage diagnosis and prognosis of cancers (Catuogno et al., 2011; Chen et al., 2008; Lawrie et al., 2008) and as indicator in cancer therapy effectiveness (Bartels and Tsongalis, 2009; Raymond et al., 2005). Consequently, it is important to develop analytical methods for the rapid and sensitive identification of miRNAs in cell or tissue and in biological fluids (Labib and Berezovski, 2015). However, the short length and the low concentration (in the nano-molar to pico-molar range) of miRNA targets are significant limiting factors when it comes to the development of new methods (Calin et al., 2005; Koshiol et al., 2010).

To date, several approaches have been used to profile miRNAs in biological samples. These include: Northern blot analysis (Kim et al., 2010; Válóczi et al., 2004), real-time PCR 
methods (Asaga et al., 2011; Chen et al., 2005; Zhang et al., 2011), micro-arrays (Thomson et al., 2004; Wang et al., 2011), in situ hybridisation (de Planell-Saguer et al., 2010), bioluminescence-based methods (Cissell et al., 2008), fluorescence correlation spectroscopy (FCS) (Neely et al., 2006), surface-enhanced Raman spectroscopy (SERS) (Driskell et al., 2008), surface plasmon resonance imaging (SPRI) (Fan et al., 2007) and high-throughput sequencing techniques (Schulte et al., 2010). These methods need expensive and sophisticated instruments, well-controlled experimental conditions, time-consuming sample pretreatment, highly skilled personnel and do not always provide the required sensitivity.

Over the last few decades, electrochemical biosensors have attracted growing interest in clinical chemistry for point-of-care diagnostics (Labib and Berezovski, 2015). Among the different possible electrochemical approaches, electrochemical impedance spectroscopy (EIS) has been recognised as a powerful tool, which facilitates label-free detection. In 2011, Peng and Gao reported an impedimetric miRNA biosensor based on the combination of $\mathrm{RuO}_{2}$ nanoparticles and the catalytic deposition of poly (3,3'-dimethoxybenzidine) (PDB) (Peng and Gao, 2011). In a related study, self-assembled monolayers of morpholino capture probes were formed on the surface of an ITO-coated glass slide (Gao et al., 2013). Hybridisation with the target miRNA resulted in significant changes in the overall surface charge; this was used to electrostatically concentrate dimethoxybenzidine at the sensor surface, which upon chemical deposition of a PDB film, increased the sensitivity of the assay. In 2013, Shen and his coworkers described an impedimetric miRNA biosensor based on a combination of selective enzymatic digestion and PDB enhancement, via the use of DANzyme label precipitation (Shen et al., 2013). Ren and his colleagues reported an impedimetric biosensor based on the combination of on surface hybridisation and enzymatic cleavage of the DNA/RNA duplex (Ren et al., 2013); the proposed approached led to a cyclic amplification process that significantly improved the assay sensitivity.

Wan et al. (Wan, 2015) reported on the use of DNAzyme, either integrated in the recognition probe or in AuNPs based tag, for the impedimetric sensitive detection of miRNA21. In the presence of miRNA-21 the DNAzyme was catalysing the precipitation of an insulating film onto the electrode surface allowing in this way detection of miRNA at the aM level.

Recently Zhang et al. (Zhang, 2016) reported on an immobilation-free impedimetric biosensor for the detection of miRNA-21. The proposed approach, that allowed detection down to sub $\mathrm{fM}$ concentration, was based on the use of specific nuclease assisted target 
recycling (DSNATR), capture probes (Cps) enrichment by the use of magnetic beads (MBs) and electrochemical impedance spectroscopy.

Despite remarkable analytical performances, these methods have been limited by the short length of miRNA, which creates significant challenges in sandwich hybridisation assays or amplification assays, necessitating the development of somewhat complicated approaches.

The use of structurally responsive molecular beacons (MB) has been shown to be a possible route to overcome target length related limitations (Kor et al., 2015; Yin et al., 2012). Molecular beacons (MBs) are oligonucleotide hybridisation probes that have the ability to report the presence of targeted nucleic acids sequences in homogeneous solutions (Zheng et al., 2015) and in a reagent-less, wash-less formats (Beni et al., 2010; Nasef et al., 2011); these is made possible by their stem-and-loop structure and by their ability to change conformation upon recognition of the target (Tyagi and Kramer, 1996).

Gold nanoparticles (AuNPs) as labels have been widely used in diagnostics and detection because of their unique characteristics, such as high surface-to-volume ratio, high surface energy, colour, plasmonic properties and their ability to function as electron conducting pathways between prosthetic groups and the electrode surface (Cao et al., 2011; Saha et al., 2012). Typically, AuNPs are coupled with biorecognition elements for the recognition of targets and to enable signal readout (Liao et al., 2009; Sanghavi and Srivastava, 2011; Zhang et al., 2010).

Herein, we report on an impedimetric biosensor for miRNA21 detection based on the combination of molecular beacons, AuNPs and surface supramolecular interaction. Highly specific, dual-function (biotin and thiol) DNA/LNA oligonucleotide probes (molecular beacons-MB) were conjugated with AuNPs to create an integrated biorecognition element / electro active label (biotin-MB-AuNPs). This facilitated a single-step target recognition and capture onto the transducer followed by highly sensitive impedimetric detection, of miRNA21.

\section{Materials and Methods}

\subsection{Materials}

Neutravidin, Streptavidin, chloroauric acid $\left(\mathrm{HAuCl}_{4}\right)$, sodium hydroxide, sodium chloride and sodium citrate were purchased from Sigma Aldrich (USA). All chemicals used in this study were of analytical reagent grade. All solutions were prepared with ultrapure (18.2 M $\Omega$ ) water from a Millipore Milli-Q water purification system (Billerica, MA). The sequence of the 
DNA/LNA MBs was taken from previous reports (Kor et al., 2015). LNA were used to improve the stability of the duplexes after hybridisation. This is especially important for the detection of short length miRNA targets. The presence of a thiol group at the 3' end of the MB allowed its immobilisation onto the AuNPs; on the other end the biotin at the 5' was use to allow the capture of the biotin-MB-AuNP/miRNA complex onto the transducer surface via interaction with immobilised neutravidin layer.

In order to facilitate the handling of the sample, RNA sequences were replaced by RNAmimics oligonucleotides (miRNA-21); these consist of DNA sequences in which thymine was replaced by desoxy uridine (Kor et al., 2015).

The RNA-mimic model, a synthetic oligonucleotide with a DNA sugar backbone and RNA pyrimidines and purines (A,U,C,G), has the advantage of being more stable when compared to RNA. DNA-DNA and DNA-RNA duplexes have different thermodynamics and stability due to the differences in backbone structure and conformations; nevertheless these differences are not significant in the case of sequences containing $50 \%$ or more of $\mathrm{dA} /(\mathrm{U} . \mathrm{T})$ (Lesnik, 1995) and in the presence of salt (Lang, 2007). The sequences used in our work contained more than $50 \%$ of $\mathrm{dA} /(\mathrm{U} . \mathrm{T})$ and all experiments were performed in $10 \mathrm{mM}$ phosphate buffer (PB) containing $500 \mathrm{mM} \mathrm{NaCl}$. Therefore, it is reasonable to suggest that under our assay conditions no significant differences, in terms of stability and duplex formation thermodynamic, can be expected using RNA-mimic instead of RNA.

The sequence of the miRNA targets were taken from miRBase (http://www.mirbase.org) and synthesised by biomers.net (Germany). LNA modified Oligonucleotide probes were obtained from Exiqon (Denmark):

$$
M B:
$$

\section{5'-/5BioTEG/GGCCGTCAACATCAGTCTGATAAGCTACGGCCTTTTTTTTTT/}

3ThioMC3-D/-3' (in bold and italics are the LNA bases)

miRNA-21:5'-UAGCUUAUCAGACUGAUGUUGA-3'

miRNA-205: 5'-UCCUUCAUUCCACCGGAGUCUGU-3'

miRNA-221: 5'-AGCUACAUUGUCUGCUGGGUUUC-3'

Oligonucleotide stock solutions $(100 \mu \mathrm{M})$ were prepared by dissolving the lyophilised synthetic sequences in filtered (filter size: $0.2 \mu \mathrm{m}$ ) MilliQ water. All stock solutions were stored at $-20{ }^{\circ} \mathrm{C}$. In order to reduce the risks of deactivation of the thiol group the stock 
solution of the MB was divided in aliquots that were stored at $-20{ }^{\circ} \mathrm{C}$ and defrosted only when needed.

\subsection{Instrumentation}

Electrochemical impedance spectroscopy (EIS) was performed using an IviumStat Potentiostat/Galvanostat (Ivium, The Netherlands) with a three-electrode cell. A glassy carbon (GC) electrode (2 $\mathrm{mm}$ in diameter, CHI Instruments) was used as the working electrode. $\mathrm{An} \mathrm{Ag} / \mathrm{AgCl}(3 \mathrm{M} \mathrm{KCl})$ reference electrode (CHI Instruments) and a platinum counter electrode were also used. All the potential values presented are versus the $\mathrm{Ag} / \mathrm{AgCl}$ (3 $\mathrm{M} \mathrm{KCl})$ reference electrode. The Faradaic impedance measurements were performed in 10 $\mathrm{mM}$ phosphate buffer (PB) containing $500 \mathrm{mM} \mathrm{NaCl}, 2.5 \mathrm{mM}$ of $\mathrm{K}_{3} \mathrm{Fe}(\mathrm{CN})_{6}$ and $2.5 \mathrm{mM}$ $\mathrm{K}_{4} \mathrm{Fe}(\mathrm{CN})_{6} ; \mathrm{pH}=7.5$. The direct current (DC) potential was set at $+0.2 \mathrm{~V}$, which is equivalent to the formal potential of the $[\mathrm{Fe}(\mathrm{CN}) 6]^{3 / 4-}$ redox probe. The amplitude of the applied sine wave potential was $5 \mathrm{mV}$. The experimental spectra, presented as Nyquist plots, were fitted with appropriate equivalent circuits using the software supported by the instrument. All experiments were performed at room temperature $\left(21^{\circ} \mathrm{C}\right)$.

UV-vis measurements were performed using a SHIMADZU UV-2450 spectrophotometer (Shimadzu, Japan) with a $0.5 \mathrm{~nm}$ resolution. The particle size of the AuNPs and biotin-MBAuNPs conjugate were measured using a Zetasizer Nano ZS90 (Malvern Instruments Ltd., Worcestershire, UK) using dynamic light scattering. The measurements were performed at 21 ${ }^{\circ} \mathrm{C}$ and the mean zeta potential values were calculated by taking an average of 3 repeated measurements.

\subsection{Preparation of gold nanoparticles (AuNPs)}

AuNPs were synthesised according to the citrate reduction of $\mathrm{HAuCl}_{4}$ according to a protocol previously reported by the authors (Beni et al., 2010). In brief, $50 \mathrm{~mL}$ of $1 \mathrm{mM}$ $\mathrm{HAuCl}_{4}$ were brought to boil under vigorous stirring. Rapid addition of $5 \mathrm{~mL}$ of a $38.8 \mathrm{mM}$ sodium citrate solution to the vortex of the solution resulted in a colour change from pale yellow to burgundy. Boiling was continued for $10 \mathrm{~min}$; the heating mantle was then removed, and stirring was continued for an additional $15 \mathrm{~min}$. After the solution cooled to room temperature it was stored at $4{ }^{\circ} \mathrm{C}$.

\subsection{Preparation of biotin-MB-AuNPs Conjugates}


Preparation of biotin-MB-AuNP conjugate was performed following a protocol previously optimised by the authors (Kor et al., 2015). Briefly; $250 \mu \mathrm{L}$ of the AuNPs (OD 2.3) in $0.1 \mathrm{mM}$ phosphate buffer at $\mathrm{pH} 7.4$ were mixed, in a $\mathrm{NaOH}$ treated glass vial, with adequate volume of the MBs stock solution in order to obtain a final DNA-to-AuNPs ratio of 500:1. The solution was then left to react at room temperature, under gentle mixing, overnight. Following this first incubation step the biotin-MB-AuNP mixture was subjected to an "aging process". This was performed at room temperature and consisted of a stepwise increase $(25,50,100,150,200,250$ and $300 \mathrm{mM})$ of the concentration of $\mathrm{NaCl}$ in the mixture solution; where each concentration of $\mathrm{NaCl}$ was obtained by adding, under gentle shaking with a 30 min interval, the required volume of a $2 \mathrm{M} \mathrm{NaCl}$ stock solution. The obtained mixture was incubated overnight at room temperature under gentle shaking. Finally, the biotin-MB-AuNP conjugates were washed twice by sequential centrifugation (8,420 g $20 \mathrm{~min}$, $21{ }^{\circ} \mathrm{C}$ ), resuspended in $0.3 \mathrm{M} \mathrm{NaCl}$ and $0.1 \mathrm{mM}$ phosphate buffer at $\mathrm{pH} 7.4$ and stored at $4{ }^{\circ} \mathrm{C}$ until use.

\subsection{Fabrication of the transducing surface}

Prior to functionalisation, the glassy carbon electrode was sequentially polished with 0.3 and $0.05 \mu \mathrm{m}$ alumina slurry, followed by ultrasonic cleaning in ethanol and ultrapure water. The electrode was then rinsed with copious amounts of double-distilled water, dried with high-purity nitrogen and used for the deposition of the protein-based capturing layer. $5 \mu \mathrm{L}$ of $1 \mathrm{mg} / \mathrm{mL}$ neutravidin solution were drop-cast onto the clean surface of the electrode, left to dry for $1 \mathrm{~h}$ at room temperature and finally cross-linked with glutaraldehyde ( $25 \%$ in water on hot plate at $40{ }^{\circ} \mathrm{C}$ ) vapour for $45 \mathrm{~min}$. The electrodes were then washed with buffer, dried and stored at $4{ }^{\circ} \mathrm{C}$. Prior to use the electrode were re-hydrated for 5 minutes with buffer solution.

\subsection{Detection of miRNA-21}

Detection of the target miRNA was performed by incubating the modified glassy carbon working electrodes in the solution containing miRNA in the presence of the biotin-MB-AuNP label for $1 \mathrm{~h}$ (optimum hybridisation time). The solution was prepared by mixing a desired amount of target miRNA with an optimised volume of biotin-MB-AuNP conjugate ( $3 \mu \mathrm{L}$, O.D. 2.3 at $520 \mathrm{~nm}$ ) in the optimum buffer $(10 \mathrm{mM}$ phosphate buffer $\mathrm{pH}$; $\mathrm{PB}$ containing 500 $\mathrm{mM} \mathrm{NaCl}, \mathrm{pH}=7.5$ ) to a final volume of $25 \mu \mathrm{L}$. During this step, several processes took place: (i) recognition of the miRNA target by the MB; (ii) subsequent activation of the biotin-MBAuNPs label, via opening of the MB and exposure of the biotin; and (iii) capture of the 
activated biotin-MB-AuNP/miRNA-21 complex onto the transducing surface. This chain of events is at the base of the proposed one-step biosensor. After incubation, the sensor was rinsed with $25 \mu \mathrm{L}$ of $10 \mathrm{mM}$ phosphate buffer solution (pH 7.4) using a miropipette.

\subsection{Preparation of spiked serum samples}

Serum was prepared from human whole blood collected from apparently healthy volunteering and consenting donors at Linköping University Hospital with ethical approval. In brief, the blood sample was allowed to clot at room temperature for $30 \mathrm{~min}$. and then centrifuged at $1500 \mathrm{~g}$ for $15 \mathrm{~min}$. The serum was obtained by collecting the top layer. The desired concentrations of miRNA-21were obtained by spiking $20 \mu \mathrm{L}$ of the serum with $2 \mu \mathrm{L}$ of appropriate miRNA-21 stock solution.

\section{Results and discussion}

\subsection{Design of the single-probe impedimetric miRNA biosensor}

Scheme 1 illustrates the working principle of the proposed impedimetric biosensor. The proposed sensor comprises two elements: i) a neutravidin modified GC electrode used to transduce the biorecognition event and ii) the biotin-MB-AuNP dual-function bio-label that allowed both biorecognition (via the hybridisation of the immobilised MB with the miRNA target) and signal generation (via the catalytic properties of the AuNPs).

There are three key aspects that regulate the generation of the signal in the proposed biosensor: i) the opening of the MB, with subsequent exposure of the biotin functionality, following the recognition of the target miRNA; ii) the capture of the miRNA-21/biotin-MBAuNPs complex onto the transducing electrode, via biotin/neutravidin interaction; and iii) the catalytic properties of the AuNPs which result in a reduction in the charge transfer resistance.

In a typical experiment, described in Scheme 1, the sample is spiked with an optimal volume of a stock solution containing the biotin-MB-AuNPs dual label. The so obtained solution is then immediately transferred onto the sensor surface and left to react for a fixed time. During this time, if target miRNA is present in the sample this will hybridise with the MB of the biotin-MB-AuNPs. This hybridisation event will result in exposing the biotin groups present at one end of the MBs making those now available for interaction with the neutravidin present onto the electrode surface with subsequent irreversible capture of the miRNA-21/biotin-MB-AuNPs complex at the electrode surface. On the other hand, in the 
absence of target miRNA the MBs will retain their closed configuration with no capture of the biotin-MB-AuNPs onto the electrode surface.

On termination of the incubation step the sensor was washed and transferred to the measurement solution and impedance spectra recorded. The presence of miRNA-21/biotinMB-AuNPs on the electrode surface will result in a significant decrease (when compared to those recorded prior to analysis) in the charge transfer resistance. Relative variations in the charge transfer resistance can then be associated to the concentration of miRNA in the sample.

\section{LOCATION SCHEME 1}

\subsection{Characterisation of the biotin-MB-AuNP label}

The hydrodynamic size of the synthesised citrate-capped AuNPs, biotin-MB-AuNP label and biotin-MB-AuNP/miRNA-21 complexes were obtained by dynamic light scattering measurements. The average hydrodynamic diameters obtained were $31 \pm 1.5,40 \pm 2.1$ and $57 \pm 1.3 \mathrm{~nm}$, respectively. An increase in hydrodynamic diameter was observed for the biotinMB-AuNPs compared with the AuNPs as it can be seen in the size distribution curve (Figure $\mathrm{S} 1$ in supporting information); this indicates the successful immobilisation of the MB onto the AuNPs. A further increase in the hydrodynamic diameter was recorded after formation of the biotin-MB-AuNP/miRNA-21 complex (Figure S1 in supporting information), indicating the opening of the MB stem-loop structure.

Zeta potential measurements, summarised in Figure 2S (supporting information), were performed to study the surface charge densities of the AuNPs, biotin-MB-AuNP label and biotin-MB-AuNP/miRNA-21 complex. Following functionalisation of the AuNPs with MBs, an increase in the zeta potential was recorded from $-33 \pm 2.5 \mathrm{mV}$ (AuNPs) to $-41 \pm 5.2 \mathrm{mV}$ (MB-AuNPs). After hybridisation with target miRNA-21, the zeta potential of the biotin-MBAuNPs/miRNA-21 complex further increased to $-50 \pm 1.3 \mathrm{mV}$. These increases in zeta potential values are related to the high negative charges of the MBs and miRNAs.

UV-Vis spectra, recorded for the AuNPs, biotin-MB-AuNP label and biotin-MBAuNP/miRNA-21 complex at high salt concentration $(0.5 \mathrm{M} \mathrm{NaCl})$, showed clear absorption peaks at 520.0, 521.4 and $522.9 \mathrm{~nm}$, respectively. Significantly, no peaks were observed at longer wavelengths indicating the stability of the biotin-MB-AuNP label at high salt concentration. These results demonstrated the successful synthesis of the biotin-MB-AuNP label and its good colloidal stability. 


\subsection{Optimisation of experimental conditions}

In order to maximise the performance of the proposed biosensing approach, optimisation of (i) the charge of the transducer surface, (ii) amount of the on-transducer

303

304

305

306

307

308

309

310

311

312

313

314

315

316

317

318

319

320

321

322

323

324

325

326

327

328

329

330

331 capturing element (immobilised neutravidin), (iii) concentration of biotin-MB-AuNPs label, and (iv) recognition / capture time was performed.

Firstly, the effect of the charge of the transducer surface was investigated by using, for the functionalisation step, proteins (neutravidin and streptavidin) with similar recognition ability but different isoelectric points. The effect of transducer surface charges was investigated by comparing the responses of the sensing surfaces for different concentrations $(0,0.5$ and $1 \mathrm{nM})$ of target miRNA-21. Assays were performed in $10 \mathrm{mM}$ phosphate buffer

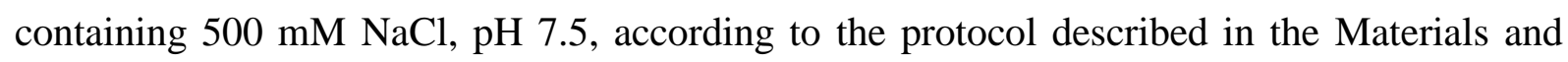
Methods section (section 2.6). As can be seen from Figure 1A, the signal observed in the case of neutravidin-modified surface was twice that recorded for the streptavidin-modified surface. This result could be associated with the electrostatic repulsion between the highly negatively charged biotin-MB-AuNP/miRNA-21 complex and the streptavidin on the surface at $\mathrm{pH} 7.5$. In contrast, the neutravidin surface remains non-charged and this facilitates the specific capturing of the biotin-MB-AuNP/miRNA-21 complex. The use of positively charged avidin was not tested since this was expected to induce significant unspecific electrostatic adsorption of the negatively charged biotin-MB-AuNPs. The results presented in Figure 1A led to the choice of neutravidin for further experiments.

To define the nature of the capturing layer, optimisation of the amount of neutravidin on the transducer surface was performed by preparing electrodes with various neutravidin concentrations ranging between 0.5 and $2 \mathrm{mg} / \mathrm{mL}$. The responses of the sensors to $0,0.5$ and 1 $\mathrm{nM}$ of target miRNA-21 are presented in Figure 1B. A closer analysis showed that, the normalised signal for the detection of $1 \mathrm{nM}$ miRNA-21increased with increasing amount of the neutravidin on the transducer surface. The maximum response was obtained for surfaces prepared using $1 \mathrm{mg} / \mathrm{mL}$ of neutravidin solution, while a slightly decreased signal response was observed when higher neutravidin concentrations where used during the functionalisation step. The decrease in signal response was mainly associated with an increase in the initial charge transfer resistance $\left(\mathrm{R}_{\mathrm{ct} t}\right)$, which was probably due to the increase in the protein layer thickness acting as a macromolecular barrier for interfacial charge transfer (Azzouzi et al., 2015). 
Following optimisation of the transducing element, the effect of the amount of biotinMB-AuNP label on the biosensor performance was investigated. 1, 2, 3 and $4 \mu \mathrm{L}$ of the stock biotin-MB-AuNPs solution (O.D. 2.3), in a $25 \mu \mathrm{l}$ of recognition/capturing solution, were used for the detection of $0,0.5$ and $1 \mathrm{nM}$ of the targeted miRNA-21. Higher normalised signals and, subsequently, better discrimination were recorded for $3 \mu \mathrm{L}$ of the biotin-MB-AuNP. In order to gain a better understanding of the results obtained, the normalised responses obtained from the different experiments were plotted and compared. As can be seen in Figure 1C, an increase in the amount of the biotin-MB-AuNPs in the recognition/capturing solution resulted in an increase in the absolute signal with no significant variation in the absolute blank signal (no target analyte) until $3 \mu \mathrm{L}$ of the biotin-MB-AuNP, while no significant improvement in signal response was observed when further increase the amount of bio-MB-AuNP. As a result of these optimisation experiments, the following parameters were adopted for further work: (i) $1 \mathrm{mg} / \mathrm{mL}$ of neutravidin as immobilisation solution and (ii) $3 \mu \mathrm{L}$ of the biotin-MB-AuNP stock solution (O.D. 2.3).

The relationship between recognition/capture time and biosensor response was also evaluated. This was investigated by detecting 0.5 and $1 \mathrm{nM}$ miRNA-21 (final concentration) using different recognition/capture times (5, 15, 30, 60, 90 and $120 \mathrm{~min}$.). Figure 1D shows that the signal response increased with increasing time, starting from $4 \%$ after $5 \mathrm{~min}$. and reaching $76 \%$ at $60 \mathrm{~min}$., then leveling off for longer times. Therefore, $60 \mathrm{~min}$. was chosen as the recognition / capturing time in order to save time while still getting a large enough signal response.

\section{LOCATION FIGURE 1}

\subsection{Analytical characteristics}

In order to investigate the analytical performance of this impedimetric biosensor, a series of calibration curves for the detection of target miRNA-21 ( 3 repetitions) in the low to high picomolar region (1 to $1000 \mathrm{pM})$ were performed. This range of concentration was selected following previous reports quantifying miRNA-21 in biological fluids (Yin et al., 2012; Zhang et al., 2011).

Figure 2A presents the typical Nyquist plots after addition of miRNA-21 standard solution, where $\mathrm{Z}^{\prime}$ is the real part and $\mathrm{Z}^{\prime \prime}$ is the imaginary part of the complex impedance $\mathrm{Z}$. Semicircle plots, characteristic of a resistance in parallel with a capacity component, were recorded (Ben Ali et al., 2006). As can be seen, the diameter of the half-circles decreases considerably with increasing miRNA-21 concentration. This could be due to the increase in 
electron transfer reflecting the capture of the biotin-MB-AuNP/miRNA complex, onto the transducer surface. The Nyquist diagrams were fitted using the equivalent circuit shown as inset in Figure2A (Barreiros dos Santos et al., 2013). Normalised relative variation of $\mathbf{R}_{c t}$ $\left(\Delta \mathrm{R}_{\mathrm{ct}} / \mathrm{R}_{\mathrm{ct} 0}\right) \%$, was used as analytical response of the biosensor. This was calculated by normalising the variation of $\mathrm{R}_{\mathrm{ct}}$ (difference between $\mathrm{R}_{\mathrm{ct}}$ for $\mathrm{x} \mathrm{pM}$ of target and no target) against $\mathrm{R}_{\mathrm{ct} 0}$ (no target). A linear calibration plot was obtained (Figure $2 \mathrm{~B}$ ) over the range 1 to $1000 \mathrm{pM}$ (with a good correlation coefficient $\mathrm{R}^{2}$ of 0.9947 ; RSD $=3.3 \%$; $\mathrm{n}=3$ ) and a low limit of detection, LOD ( $0.3 \mathrm{pM}$ defined as $3 \sigma /$ slope; $\mathrm{n}=3)$. The recorded dynamic range and the low LOD suggest that the proposed biosensor is suitable for the detection of miRNA at clinically relevant concentrations (Yin et al., 2012).

\section{LOCATION FIGURE 2}

A comparison with selected literature is presented in Table 1. As it can be seen from this table the approach proposed in this work exhibits one of the larger dynamic ranges; furthermore the proposed method, despite not presenting the best limit of detection, allowed the single-step amplification free detection of miRNA-21 within clinically relevant concentration range for cancer patients (Yin et al., 2012). This performance clearly highlights the potentiality and the advantages of the reported method when it comes to real practical applications not requiring the use of multiple amplification steps and reagents. Moreover, the possibility of performing amplification-free is a significant advantage when it comes to the detection of short length target as miRNA.

\section{LOCATION REVISED TABLE 1}

The robustness of the assay was evaluated over a period of 28 days. This evaluation was performed by measuring the response to $0.5 \mathrm{nM}$ of miRNA-21 using the neutravidin-modified electrodes and biotin-MB-AuNPs label stored for between 0 and 28 days, according to the conditions described in the Materials and Methods section. The biosensing platform was relatively robust, retaining ca $90 \%$ of its initial response (see Figure 2C) thus demonstrating the stability of the transducer surface and of the biotin-MB-AuNPs label. 
The reproducibility of the assay was also investigated by evaluating the intra- and interassay coefficients of variations (CV). The intra-assay $\mathrm{CV}$ was determined by performing repeated measurements of the same batch of biotin-MB-AuNPs and the inter-assay CV was determined by performing repeated measurements using three different batches of biotin-MBAuNPs label. Due to the non-reusability of the transducer surface, each series of measurements was performed with freshly prepared neutravidin-modified GC electrodes. The intra-assay CVs, for detection of 0.5 and $1.0 \mathrm{nM}$ of miRNA-21, were $3.9 \%$ and $3.1 \%$, respectively. The inter-assay CVs for detection of the same miRNA-21 concentrations were $4.2 \%$ and $4.6 \%$, respectively. The reproducibility of the transducer surfaces was obtained by comparing the initial $\mathrm{R}_{\mathrm{ct}}$ responses of 9 electrodes and yielded an inter-electrode $\mathrm{CV}$ of $4.5 \%$. The low CVs of below 5\%, confirmed the good reproducibility of the assay.

\subsection{Selectivity}

The selectivity of the impedimetric biosensor towards miRNA-21 was evaluated by comparing the signal responses with two other miRNA (miRNA-221 and miRNA-205), which have both been demonstrated to be overexpressed in relation to cancers; miRNA-205 in breast (Greene et al., 2010), prostate (Majid et al., 2010), lung(Markou et al., 2008) and bladder (Wiklund et al., 2011) cancers and miRNA-221 in bladder (Lu et al., 2010) and a strocytic tumours (Conti et al., 2009). Figure 3A shows that a clear response was observed in the presence of target miRNA-21 (1 pM) while no significant signal was observed for either miRNA-205 (with $41 \%$ similarity) or for miRNA-221 (with $18 \%$ similarity) or mixture of them even if tested at significantly higher concentration $(1 \mathrm{nM})$ or co-existing in large excesses $(1000+1000$ folds $)$. This result confirms the high specificity of the MB in biotinMB-AuNP label towards miRNA-21.

\section{LOCATION FIGURE 3}

\subsection{Analysis of spiked serum samples}

Detection of miRNA-21 in real samples was investigated using standard addition in spiked serum. Serum samples with miRNA-21 concentrations of 5, 10 and $150 \mathrm{pM}$ were prepared and measured (as described in section 2.6). Serum sample with a background level of miRNA-21 equal to $5 \mathrm{pM}$ was incubated in the sensor and the signal fitted to the calibration curve in Figure $2 \mathrm{~B}$ to calculate an approximate concentration value. After this, 
solutions containing approximately twice and three times the calculated preliminary concentration were prepared by spiking the sample with adequate volumes of a miRNA-21 stock solution. The responses obtained for the sample and for the spiked solutions were then plotted and miRNA-21 concentration in sample was calculated by extrapolating the linear curve, obtained by plotting the responses vs the nominal concentration of added stock miRNA-21, to $\mathrm{Y}=0$ and using the absolute value of the calculated $\mathrm{X}$ as the target concentration. The measured concentration level obtained was $7.6 \pm 0.4 \mathrm{pM}$, corresponding to a relative error of $5.2 \%$. A similar procedure was used for the detection of samples spiked with 10 and $150 \mathrm{pM}$ of miRNA-21. The measured and the actual concentration of miRNA-21 in the spiked serum samples are compared in Table 1 and the correlation plot (measured concentration using the standard addition method $v s$ the actual concentration) is shown in Figure 3B. As it can be seen from Table 2 and Figure 3B (slope of 0.92; $R^{2}=0.999$ ), there was a good match between the measured experimental values and the nominal concentration of the miRNA-21 in the serum samples. Thus, the impedimetric biosensor allowed accurate detection of miRNA-21 at low pM concentration not only in buffer solutions, but also in serum samples that resemble well likely clinical samples.

\section{LOCATION TABLE 2}

\section{Conclusion}

We report the development and evaluation of an impedimetric biosensor for the detection of miRNA21 based on an integrated dual functional probe (biotin-MB-AuNPs) and a neutravidin modified transducer surface. The biosensor responded linearly to miRNA-21 over a concentration range of 1 to $1000 \mathrm{pM}$, with a limit of detection of $0.3 \mathrm{pM}$. It was highly reproducible $(\mathrm{RSD}=3.3 \%)$ with intra-assay and inter-assay $\mathrm{CV}$ s below $10 \%$. The biosensor had high selectivity for miRNA-21 in comparison of other ontologically relevant miRNA targets (miRNA-221 and miRNA-205). Furthermore, the use of neutravidin, when compared to streptavidin, as a recognition element on the electrode surface was shown to be beneficial for the overall sensor performance and significantly improved the sensitivity. Clinically relevant levels of miRNA-21 were detected in spiked serum sample. We propose this impedimetric biosensor design for the rapid, robust and simple screening of nucleic acid tumour markers. 


\section{5. Acknowledgement}

467 This work was partially funded by the "SMARTCANCERSENS" project from the 468 European Communities Seventh Framework Program under the Grant Agreement PIRSES469 GA-2012-318053.

470 
472

473

474

475

476

477

478

479

480

481

482

483

484

485

486

487

488

489

490

491

492

493

494

495

496

497

498

499

500

501

502

503

\section{References}

Asaga, S., Kuo, C., Nguyen, T., Terpenning, M., Giuliano, A.E., Hoon, D.S.B., 2011. Clin. Chem. 57, 84-91.

Azzouzi, S., Rotariu, L., Benito, A.M., Maser, W.K., Ben Ali, M., Bala, C., 2015. Biosens. Bioelectron. 69, 280-286.

Barreiros dos Santos, M., Agusil, J.P., Prieto-Simón, B., Sporer, C., Teixeira, V., Samitier, J., 2013. Biosens. Bioelectron. 45, 174-180.

Bartels, C.L., Tsongalis, G.J., 2009. Clin. Chem. 55, 623-631.

Ben Ali, M., Korpan, Y., Gonchar, M., El'skaya, A., Maaref, M.A., Jaffrezic-Renault, N., Martelet, C., 2006. FBiosens. Bioelectron. 22, 575-581.

Beni, V., Hayes, K., Lerga, T.M., O’Sullivan, C.K., 2010. Biosens. Bioelectron. 26, 307-313.

Calin, G.A., Ferracin, M., Cimmino, A., Di Leva, G., Shimizu, M., Wojcik, S.E., Iorio, M.V.,

Visone, R., Sever, N.I., Fabbri, M., Iuliano, R., Palumbo, T., Pichiorri, F., Roldo, C., Garzon, R., Sevignani, C., Rassenti, L., Alder, H., Volinia, S., Liu, C., Kipps, T.J., Negrini, M., Croce, C.M., 2005. N. Engl. J. Med. 353, 1793-1801. Cao, X., Ye, Y., Liu, S., 2011. Anal. Biochem. $417,1-16$.

Catuogno, S., Esposito, C.L., Quintavalle, C., Cerchia, L., Condorelli, G., De Franciscis, V., 2011.. Cancers 3, 1877-1898.

Chen, C., Ridzon, D.A., Broomer, A.J., Zhou, Z., Lee, D.H., Nguyen, J.T., Barbisin, M., Xu, N.L., Mahuvakar, V.R., Andersen, M.R., Lao, K.Q., Livak, K.J., Guegler, K.J., 2005.. Nucleic Acids Res. 33, e179.

Chen, X., Ba, Y., Ma, L., Cai, X., Yin, Y., Wang, K., Guo, J., Zhang, Y., Chen, J., Guo, X., Li, Q., Li, X., Wang, W., Zhang, Y., Wang, J., Jiang, X., Xiang, Y., Xu, C., Zheng, P., Zhang, J., Li, R., Zhang, H., Shang, X., Gong, T., Ning, G., Wang, J., Zen, K., Zhang, J., Zhang, C.Y., 2008. Cell Res. 18, 997-1006.

Cissell, K.A., Rahimi, Y., Shrestha, S., Hunt, E.A., Deo, S.K., 2008. Anal. Chem. 80, 23192325.

Conti, A., Aguennouz, M., La Torre, D., Tomasello, C., Cardali, S., Angileri, F.F., Maio, F., Cama, A., Germanò, A., Vita, G., Tomasello, F., 2009. J. Neurooncol. 93, 325-332.

De Planell-Saguer, M., Rodicio, M.C., Mourelatos, Z., 2010. Nat. Protoc. 5, 1061-1073.

Driskell, J.D., Seto, A.G., Jones, L.P., Jokela, S., Dluhy, R.A., Zhao, Y.-P., Tripp, R.A., 2008. Biosens. Bioelectron. 24, 917-922. 
504 Fan, Y., Chen, X., Trigg, A.D., Tung, C., Kong, J., Gao, Z., 2007. J. Am. Chem. Soc. 129, $505 \quad 5437-5443$.

506 Gao, Z., Deng, H., Shen, W., Ren, Y., 2013. Anal. Chem. 85, 1624-1630.

507 Greene, S.B., Herschkowitz, J.I., Rosen, J.M., 2010. RNA Biol. 7, 300-304.

508

Johnson, C.D., Esquela-Kerscher, A., Stefani, G., Byrom, M., Kelnar, K., Ovcharenko, D.,

509

Wilson, M., Wang, X., Shelton, J., Shingara, J., Chin, L., Brown, D., Slack, F.J., 2007. Cancer

510

Res. 67, 7713-7722.

511 Kim, S.W., Li, Z., Moore, P.S., Monaghan, A.P., Chang, Y., Nichols, M., John, B., 2010.

512 Nucleic Acids Res. 38, e98.

513 Kor, K., Turner, A.P.F., Zarei, K., Atabati, M., Beni, V., Mak, W.C., 2015. Anal. Bioanal.

514 Chem. 408, 1475-1485.

515 Koshiol, J., Wang, E., Zhao, Y., Marincola, F., Landi, M.T., 2010. Cancer Epidemiol.

516 Biomark. Prev. Publ. Am. Assoc. Cancer Res. Cosponsored Am. Soc. Prev. Oncol. 19, 907-

517911.

518 Lang, B.E., Schwarz, F.P., 2007. Biophys Chem 131(1-3), 96-104.

519 Labib, M., Berezovski, M.V., 2015. El Biosens. Bioelectron. 68, 83-94.

520 Lawrie, C.H., Gal, S., Dunlop, H.M., Pushkaran, B., Liggins, A.P., Pulford, K., Banham,

521 A.H., Pezzella, F., Boultwood, J., Wainscoat, J.S., Hatton, C.S.R., Harris, A.L., 2008. Br. J.

522 Haematol. 141, 672-675.

523 Lesnik, A.E., Freier, S.M., 1995. Biochemistry 34(34), 10807-10815.

524 Liao, K.-T., Cheng, J.-T., Li, C.-L., Liu, R.-T., Huang, H.-J., 2009. Biosens. Bioelectron. 24, 525 1899-1904.

526 Liu, X., He, S., Skogerbø, G., Gong, F., Chen, R., 2012.. PLoS ONE 7.

527 Lu, Q., Lu, C., Zhou, G.-P., Zhang, W., Xiao, H., Wang, X.-R., 2010. Urol. Oncol. 28, 635528641.

529 Lu, Z., Liu, M., Stribinskis, V., Klinge, C.M., Ramos, K.S., Colburn, N.H., Li, Y., 2008.

530 Oncogene 27, 4373-4379.

531 Majid, S., Dar, A.A., Saini, S., Yamamura, S., Hirata, H., Tanaka, Y., Deng, G., Dahiya, R., 532 2010. Cancer 116, 5637-5649.

533 Markou, A., Tsaroucha, E.G., Kaklamanis, L., Fotinou, M., Georgoulias, V., Lianidou, E.S., 534 2008.. Clin. Chem. 54, 1696-1704.

535 Nasef, H., Beni, V., O’Sullivan, C.K., 2011. J. Electroanal. Chem. 662, 322-327. 
536

537

538

539

540

541

542

543

544

545

546

547

548

549

550

551

552

553

554

555

556

557

558

559

560

561

562

563

564

565

566

567

568

569

Neely, L.A., Patel, S., Garver, J., Gallo, M., Hackett, M., McLaughlin, S., Nadel, M., Harris, J., Gullans, S., Rooke, J., 2006. Nat. Methods 3, 41-46.

Peng, Y., Gao, Z., 2011. Anal. Chem. 83, 820-827.

Raymond, C.K., Roberts, B.S., Garrett-Engele, P., Lim, L.P., Johnson, J.M., 2005. RNA N. Y. N 11, 1737-1744.

Ren, Y., Deng, H., Shen, W., Gao, Z., 2013. Anal. Chem. 85, 4784-4789.

Saha, K., Agasti, S.S., Kim, C., Li, X., Rotello, V.M., 2012. Chem. Rev. 112, 2739-2779.

Sanghavi, B.J., Srivastava, A.K., 2011. Anal. Chim. Acta 706, 246-254.

Schulte, J.H., Marschall, T., Martin, M., Rosenstiel, P., Mestdagh, P., Schlierf, S., Thor, T., Vandesompele, J., Eggert, A., Schreiber, S., Rahmann, S., Schramm, A., 2010. Deep Nucleic Acids Res. 38, 5919-5928.

Shen, W., Deng, H., Ren, Y., Gao, Z., 2013. Biosens. Bioelectron. 44, 171-176.

Thomson, J.M., Parker, J., Perou, C.M., Hammond, S.M., 2004. Nat. Methods 1, 47-53.

Tyagi, S., Kramer, F.R., 1996. Nat. Biotechnol. 14, 303-308.

Válóczi, A., Hornyik, C., Varga, N., Burgyán, J., Kauppinen, S., Havelda, Z., 2004.. Nucleic Acids Res. 32, e175.

Wan, J., Liu, X., Zhang, Y., Gao, Q., Qi, H., Zhang, C., 2015. Sensor Actuator B, 213, 409416.

Wang, Z.-X., Bian, H.-B., Wang, J.-R., Cheng, Z.-X., Wang, K.-M., De, W., 2011. J. Surg. Oncol. 104, 847-851.

Wienholds, E., Kloosterman, W.P., Miska, E., Alvarez-Saavedra, E., Berezikov, E., de Bruijn, E., Horvitz, H.R., Kauppinen, S., Plasterk, R.H.A., 2005. Science 309, 310-311.

Wiklund, E.D., Bramsen, J.B., Hulf, T., Dyrskjøt, L., Ramanathan, R., Hansen, T.B., Villadsen, S.B., Gao, S., Ostenfeld, M.S., Borre, M., Peter, M.E., Ørntoft, T.F., Kjems, J., Clark, S.J., 2011. Int. J. Cancer J. Int. Cancer 128, 1327-1334.

Yin, H., Zhou, Y., Zhang, H., Meng, X., Ai, S., 2012. Biosens. Bioelectron. 33, 247-253.

Zhang, D., Huarng, M.C., Alocilja, E.C., 2010.. Biosens. Bioelectron., 26, 1736-1742.

Zhang, H.-L., Yang, L.-F., Zhu, Y., Yao, X.-D., Zhang, S.-L., Dai, B., Zhu, Y.-P., Shen, Y.-J., Shi, G.-H., Ye, D.-W., 2011. The Prostate 71, 326-331.

Zhang, J., Wu, D.-Z., Cai, S.-X., Chen, M., Xia, Y.-K., Wu, F.,Jing-Hua Chen, J.-H., 2016. Biosens. Bioelectron., 75, 452-457

Zheng, J., Yang, R., Shi, M., Wu, C., Fang, X., Li, Y., Li, J., Tan, W., 2015. Chem. Soc. Rev. 44, 3036-3055. 


\section{Scheme, Figures and Table caption}

Scheme 1. Assay design and detection principle of the proposed miRNA impedimetric assay based on the use of dual functional recognition/amplification bio-label.

Figure 1. (A) Effect of the charge of the electrode capturing layer on the sensor response. (B) Optimisation of the amount of immobilised neutravidin. (C) Sensor normalised response towards $0,0.5$ and $1 \mathrm{nM}$ of target miRNA-21 in the presence of different AuNP-MB bio-label loading (D) effect of the recognition/capture time on the response of the impedimetric biosensor $(\mathrm{pH}=7.5,10 \mathrm{mM}$ phosphate buffer $(\mathrm{PB})$ containing $500 \mathrm{mM} \mathrm{NaCl}, 2.5 \mathrm{mM}$ of $\mathrm{K}_{3} \mathrm{Fe}(\mathrm{CN})_{6}$ and $\left.2.5 \mathrm{mM} \mathrm{K}_{4} \mathrm{Fe}(\mathrm{CN})_{6}\right)$.

Figure 2. (A) Impedimetric response, presented as Nyquist plots, towards increasing concentrations of target miRNA-21 (B) Calibration curve as a function of miRNA concentration $(n=3)(C)$. The stability of the biosensing assay over a period of 28 days on storage at room temperature $(\mathrm{pH}=7.5,10 \mathrm{mM}$ phosphate buffer $(\mathrm{PB})$ containing $500 \mathrm{mM}$ $\mathrm{NaCl}, 2.5 \mathrm{mM}$ of $\mathrm{K}_{3} \mathrm{Fe}(\mathrm{CN})_{6}$ and $\left.2.5 \mathrm{mM} \mathrm{K}_{4} \mathrm{Fe}(\mathrm{CN})_{6}\right)$.

Figure 3. (A) Selectivity studies showing the normalised signal response for detection of target miRNA-21; non-specific miRNA-221 and miRNA-205; and miRNA-21 mixed with miRNA-221 and miRNA-205. (B) A correlation plot between the measured and the actual concentration of miRNA-21 in spiked serum samples $(\mathrm{pH}=7.5,10 \mathrm{mM}$ phosphate buffer (PB) containing $500 \mathrm{mM} \mathrm{NaCl}, 2.5 \mathrm{mM}$ of $\mathrm{K}_{3} \mathrm{Fe}(\mathrm{CN})_{6}$ and $\left.2.5 \mathrm{mM} \mathrm{K} 4 \mathrm{Fe}(\mathrm{CN})_{6}\right)$.

Table 1: Comparison of the analytical performances of the proposed impedimetric microRNA detection approach with previous reports. * Used enzymatic/NP based post hybridisation amplification step. \# Required several steps prior to measurement.

Table 2: Actual and measured concentration of target miRNA-21 in spiked serum samples. 

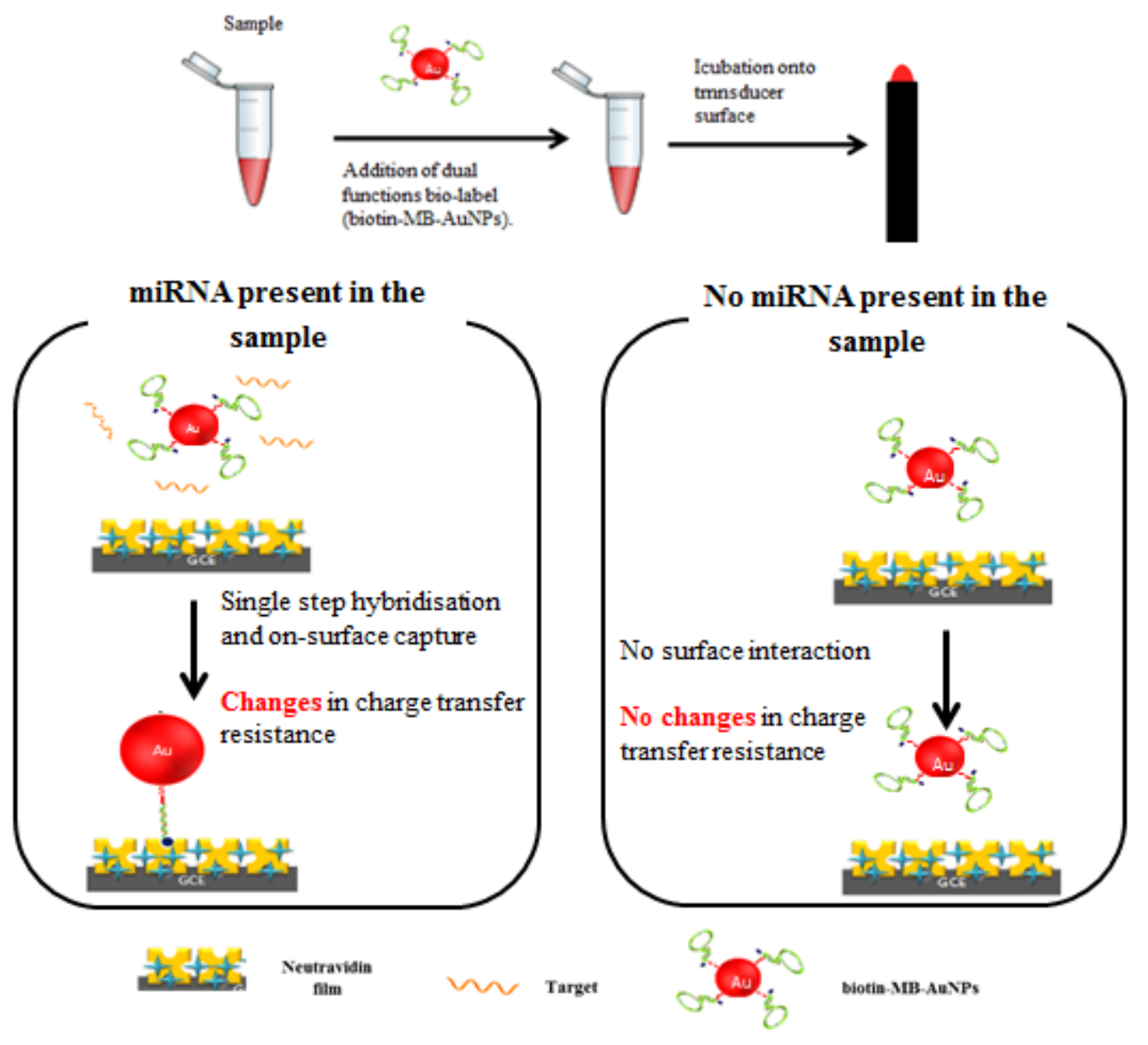

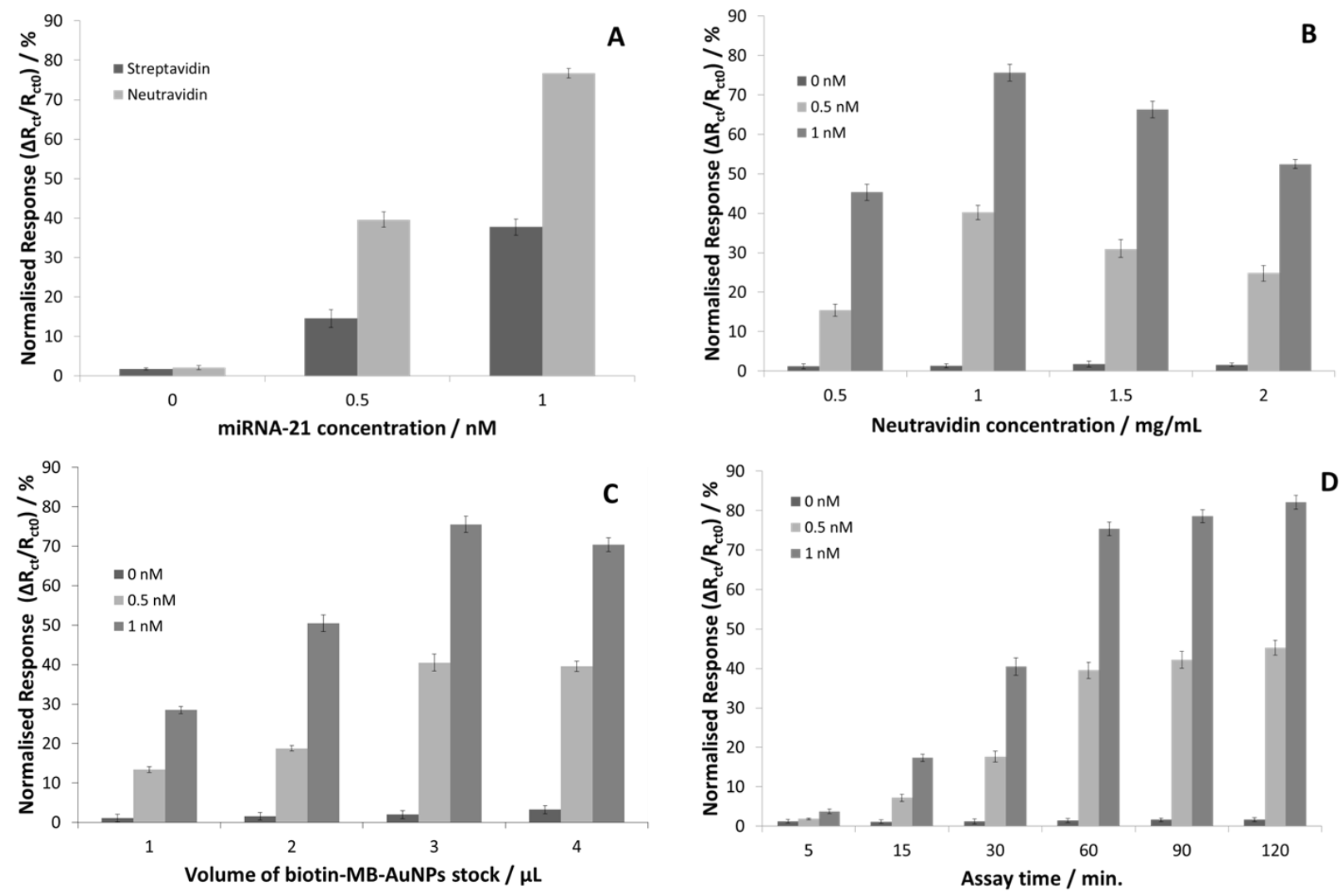
609
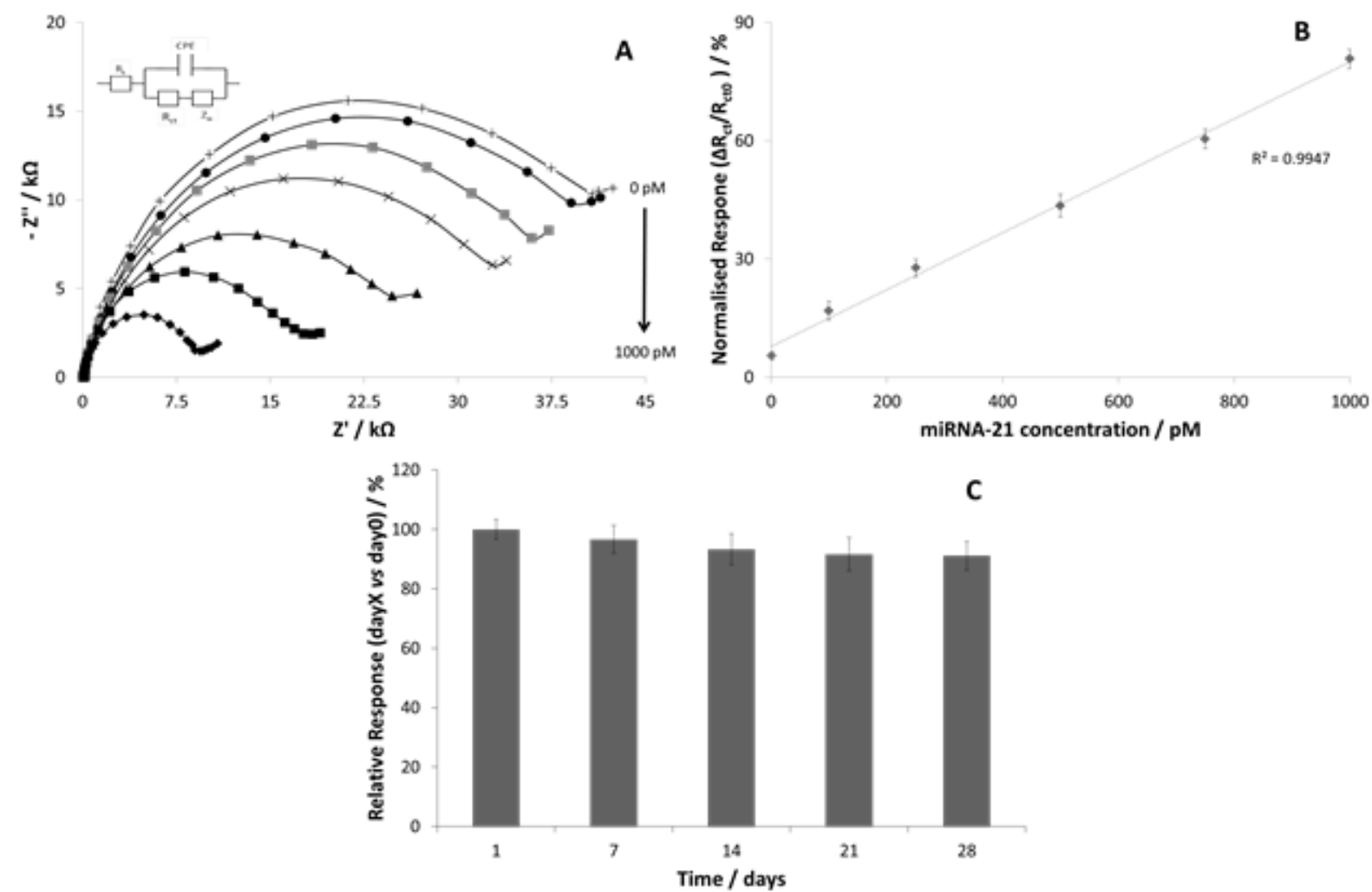

610

611

612

Figure 2

613 

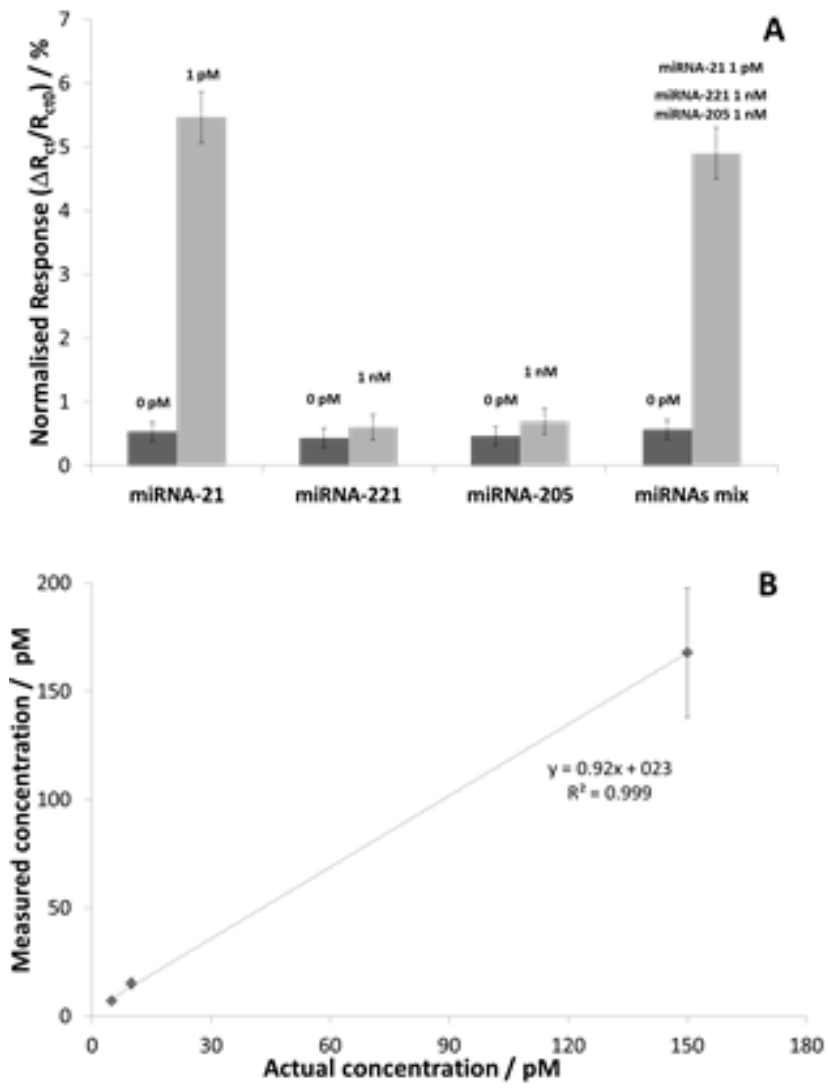

615

616

617

Figure 3

618 


\begin{tabular}{|c|c|c|c|c|}
\hline $\begin{array}{c}\text { Description of main aspect of } \\
\text { the described sensor }\end{array}$ & $\begin{array}{l}\text { Target } \\
\text { miRNA }\end{array}$ & $\begin{array}{l}\text { Linear } \\
\text { Range } \\
\text { (M) }\end{array}$ & $\begin{array}{l}\text { Detection } \\
\text { Limit } \\
\text { (M) }\end{array}$ & Ref. \\
\hline $\begin{array}{l}\text { On surface single step hybridisation } \\
\text { Post hybridisation amplification by } \\
\mathrm{RuO}_{2} \text {-catalysed deposition of PDB }\end{array}$ & $\begin{array}{c}\text { miRNA-720 } \\
\text { miRNA- } \\
1248 \\
\text { Let-7c }\end{array}$ & $\begin{array}{l}6.10^{-15}- \\
2.10^{-12}\end{array}$ & $3.10^{-15}$ & $\begin{array}{l}\text { (Peng and } \\
\text { Gao, } \\
2011)^{*}\end{array}$ \\
\hline $\begin{array}{l}\text { On surface single step hybridisation } \\
\text { Post hybridisation amplification by } \\
\text { horseradish peroxidase catalysed } \\
\text { deposition of PDB }\end{array}$ & Let-7c & $\begin{array}{l}5.10^{-15}- \\
2.10^{-12}\end{array}$ & $2.10^{-15}$ & $\begin{array}{l}\text { (Gao, } \\
2013)^{*}\end{array}$ \\
\hline $\begin{array}{c}\text { On surface multiple steps } \\
\text { hybridisation } \\
\text { Post hybridisation amplification by } \\
\text { DNAzyme-catalysed and miRNA- } \\
\text { guided deposition of PDB }\end{array}$ & Let-7c & $\begin{array}{c}5.10^{-15}- \\
10^{-12}\end{array}$ & $2.10^{-15}$ & $\begin{array}{l}\text { (Shen, } \\
\text { 2013)*\# }\end{array}$ \\
\hline $\begin{array}{c}\text { On surface hybridisation } \\
\text { Post hybridisation by duplex-specific } \\
\text { nuclease (DSN) digestion }\end{array}$ & Let-7b & $\begin{array}{l}2.10^{-15} \\
2.10^{-12}\end{array}$ & $1.10^{-15}$ & $\begin{array}{l}(\text { Ren, } \\
2013)^{*}\end{array}$ \\
\hline $\begin{array}{c}\text { On surface multiple steps } \\
\text { hybridisation } \\
\text { DNAzyme tag initiated deposition of } \\
\text { an insulating film }\end{array}$ & miRNA-26a & $\begin{array}{c}3.10^{-17}- \\
10^{-14}\end{array}$ & $15.10^{-17}$ & $\begin{array}{l}\text { (Wan, } \\
\text { 2015)*\# }\end{array}$ \\
\hline Immobilisation free detection of & miRNA-21 & $5.10^{-16}$ & $6.10^{-17}$ & (Zhang, \\
\hline
\end{tabular}




\begin{tabular}{|c|c|c|c|c|}
\hline miRNA & & $4.10^{-14}$ & & \\
$\begin{array}{c}\text { Multiple step process (hybridisation, } \\
\text { enzymatic digestion, MBs capture) }\end{array}$ & & & & \\
\hline $\begin{array}{c}\text { recognition/amplification bio-label } \\
\text { (biotin-MB-AuNPs) }\end{array}$ & miRNA-21 & $10^{-12}-10^{-9}$ & $3.10^{-13}$ & This work \\
\hline
\end{tabular}

621

622

Table 1

623 


\begin{tabular}{|c|c|}
\hline $\begin{array}{c}\text { Actual concentration } \\
\text { Measured concentration } \\
(\mathbf{n = 3})\end{array}$ \\
\hline $\mathbf{5} \mathbf{~ p M}$ & $7.1 \pm 1.2(\mathrm{RSD}=16.9 \%)$ \\
\hline $\mathbf{1 0} \mathbf{~ p M}$ & $15.1 \pm 2.4(\mathrm{RSD}=15.9 \%)$ \\
\hline $\mathbf{1 5 0} \mathbf{~ p M}$ & $167.8 \pm 29.8(\mathrm{RSD}=17.7 \%)$ \\
\hline
\end{tabular}

626

627

Table 2

628

629 


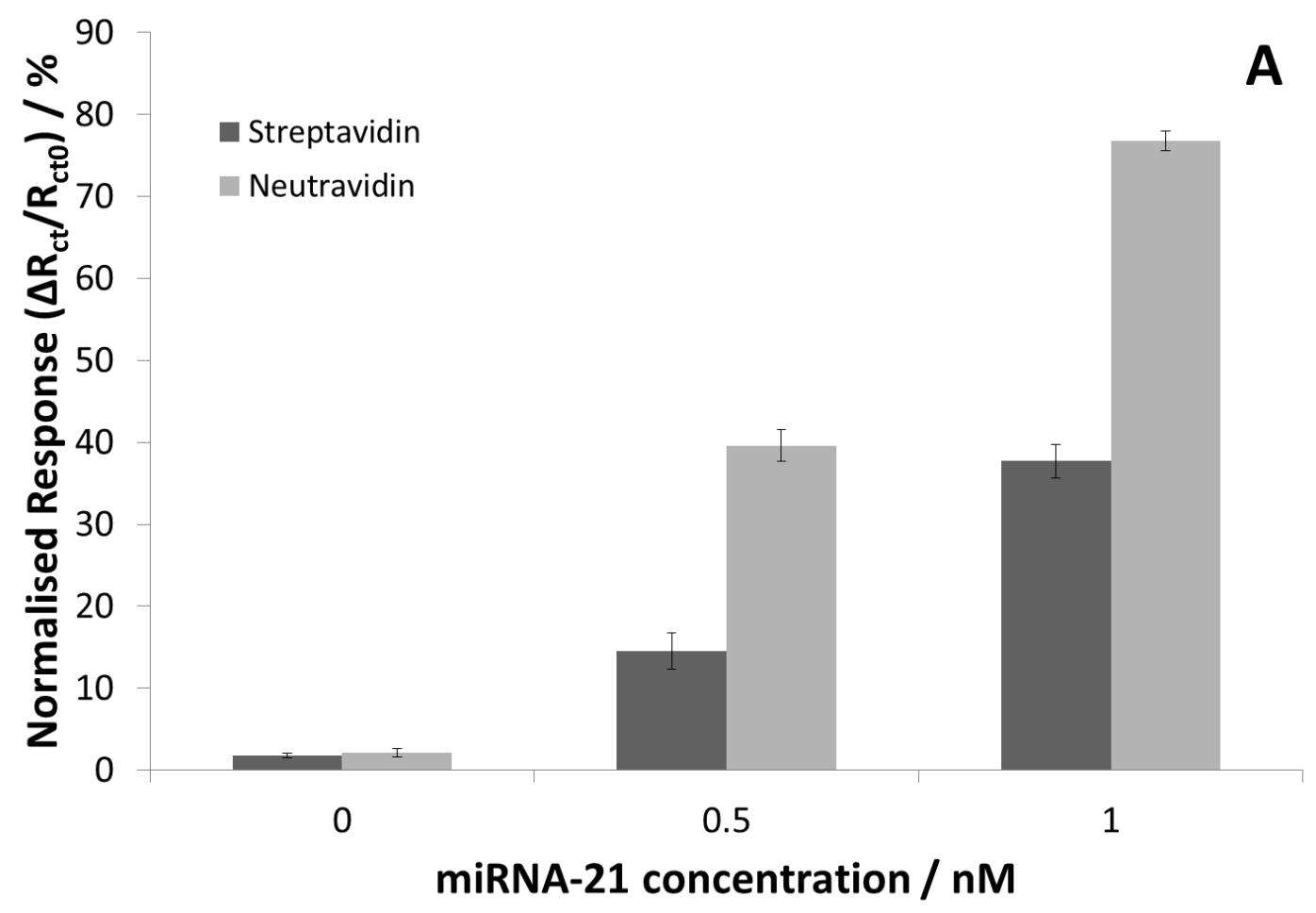

631

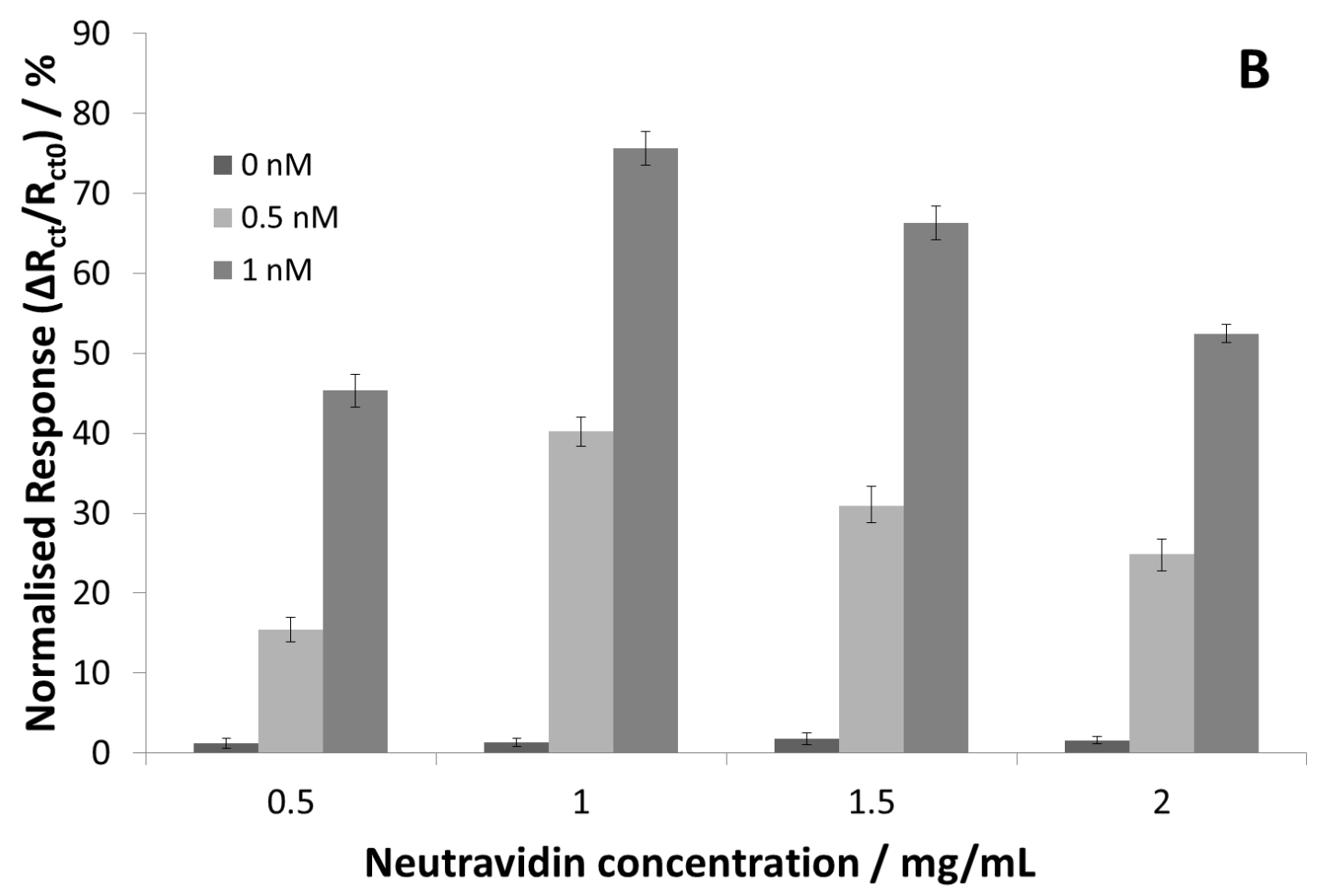




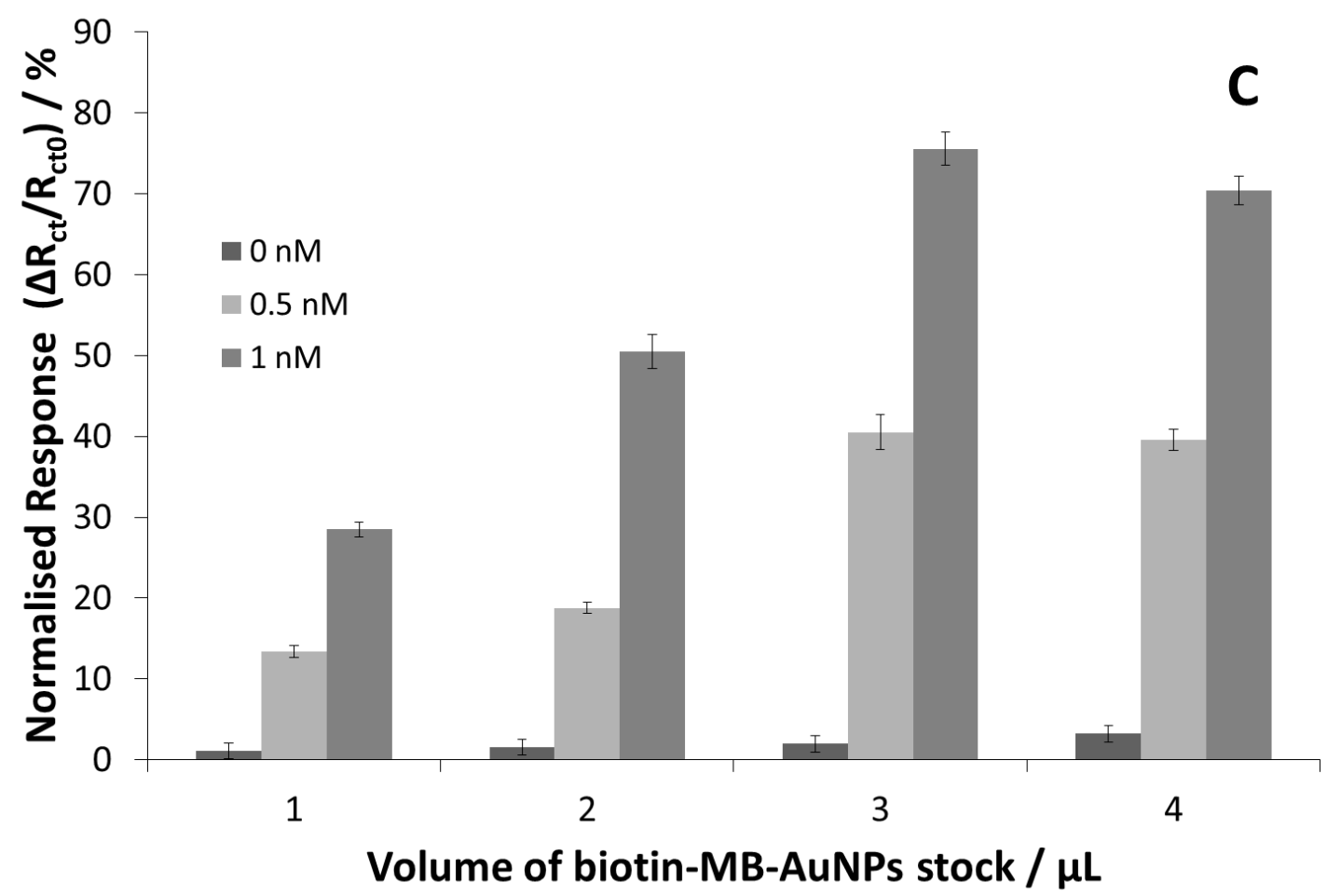

637

638

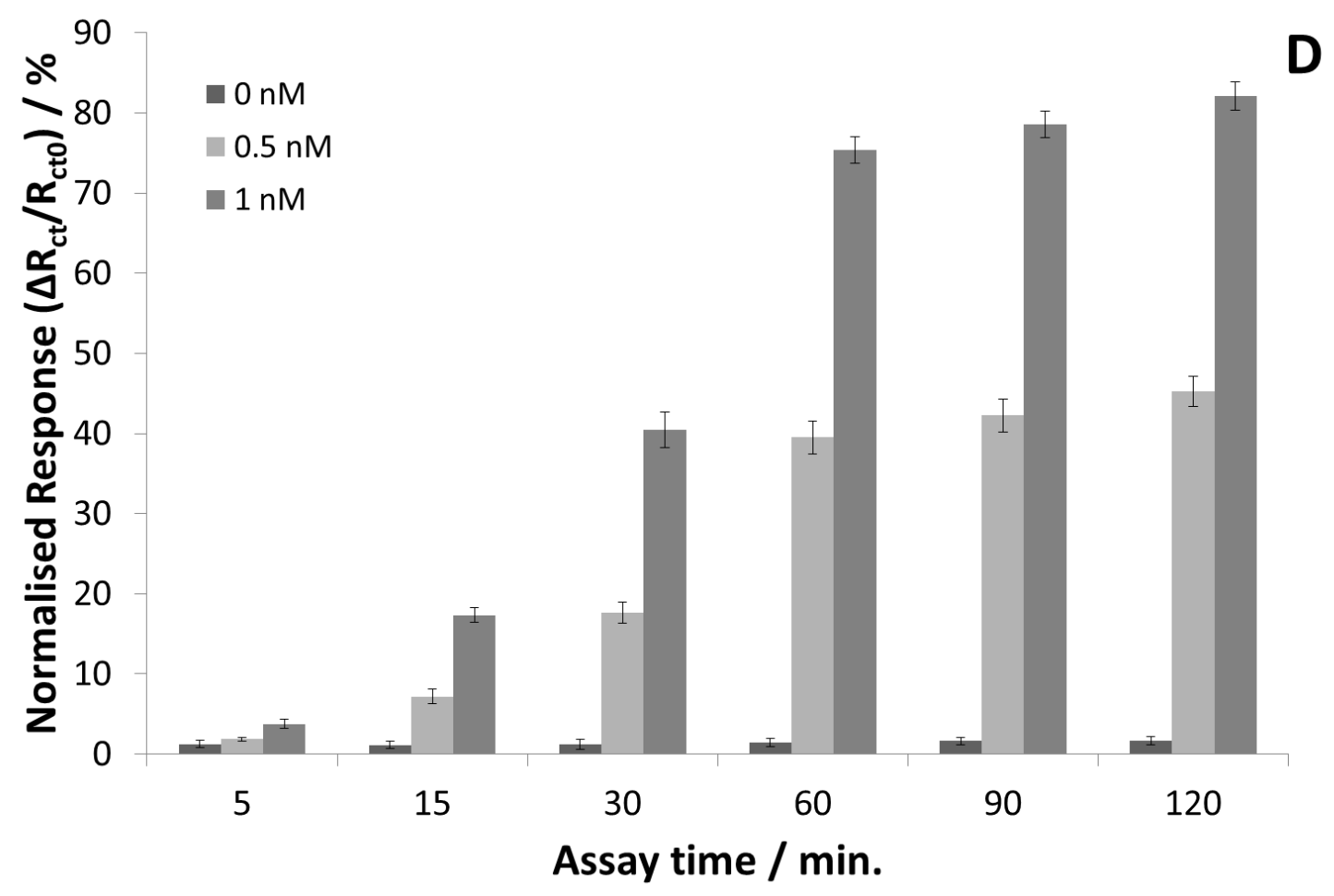




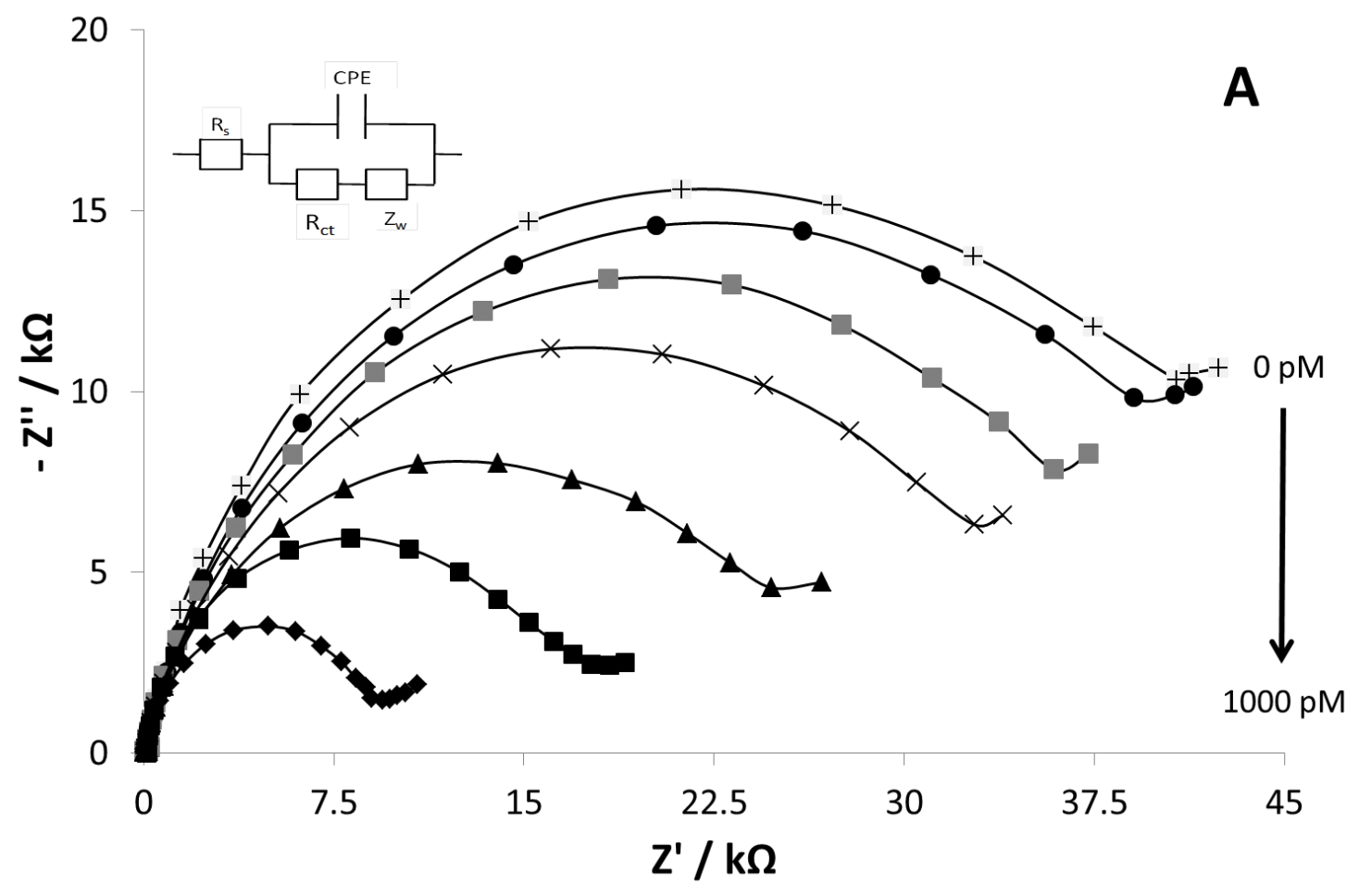

644

645

646

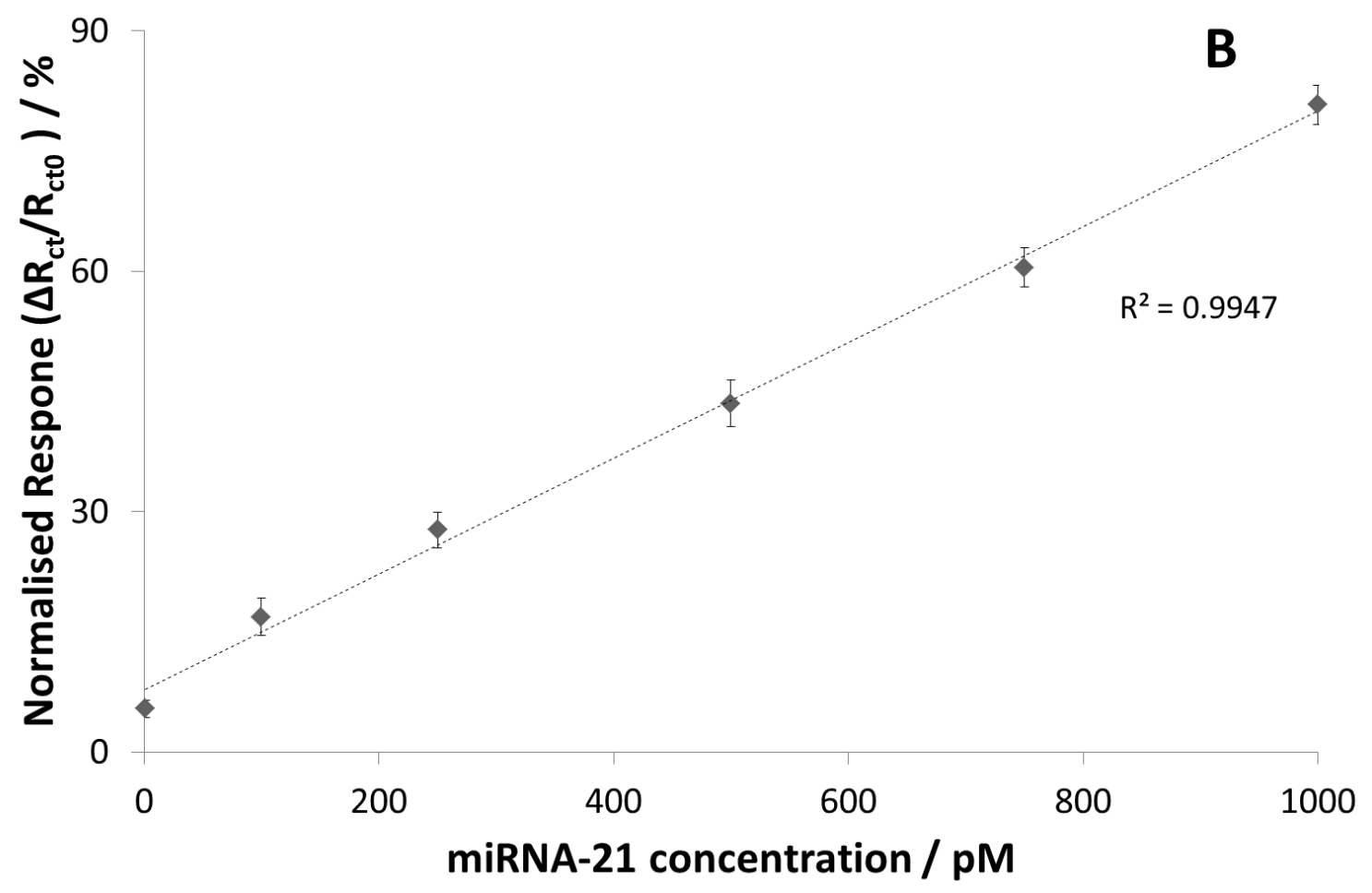




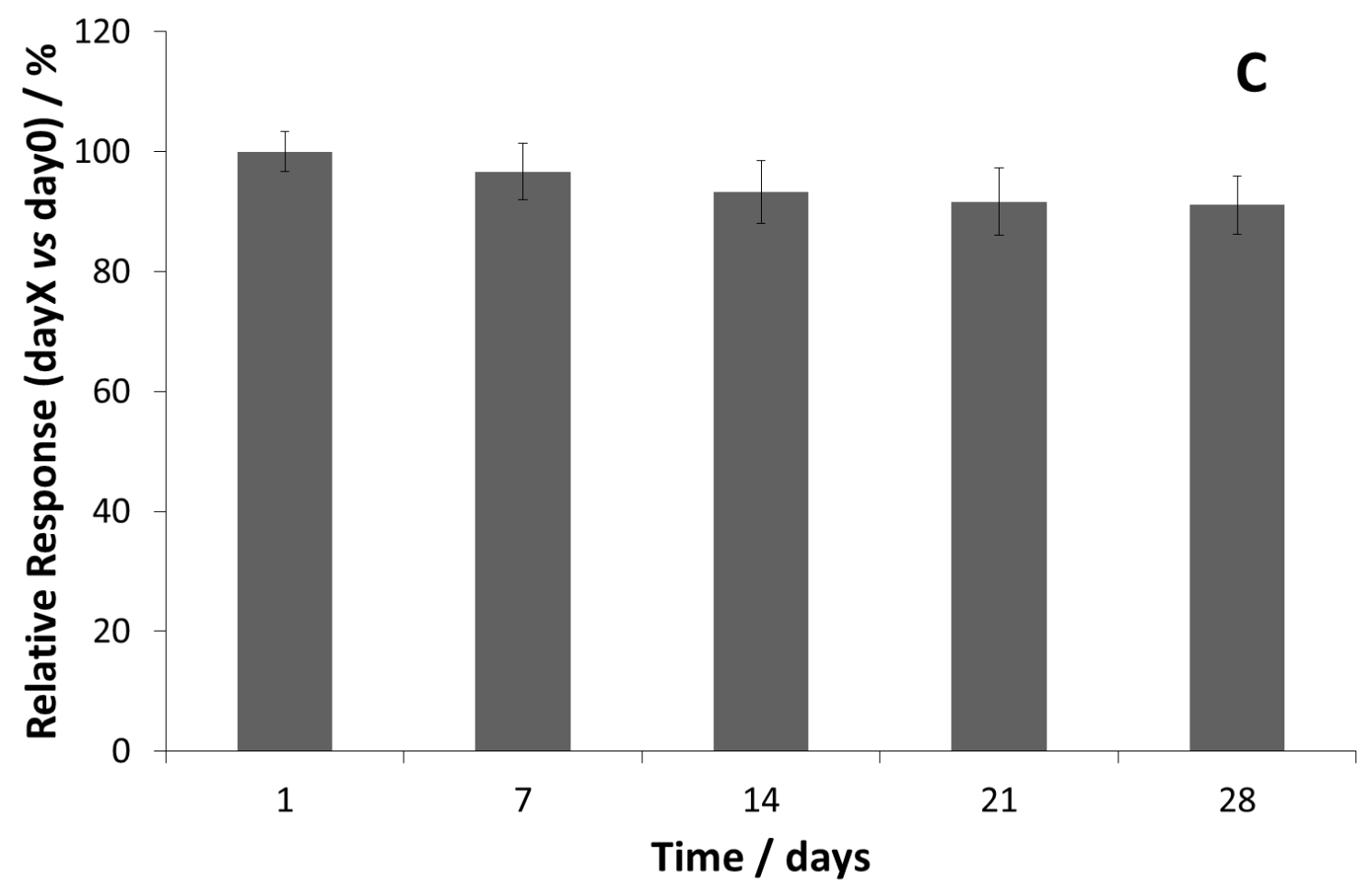

650

Figure 2

653 


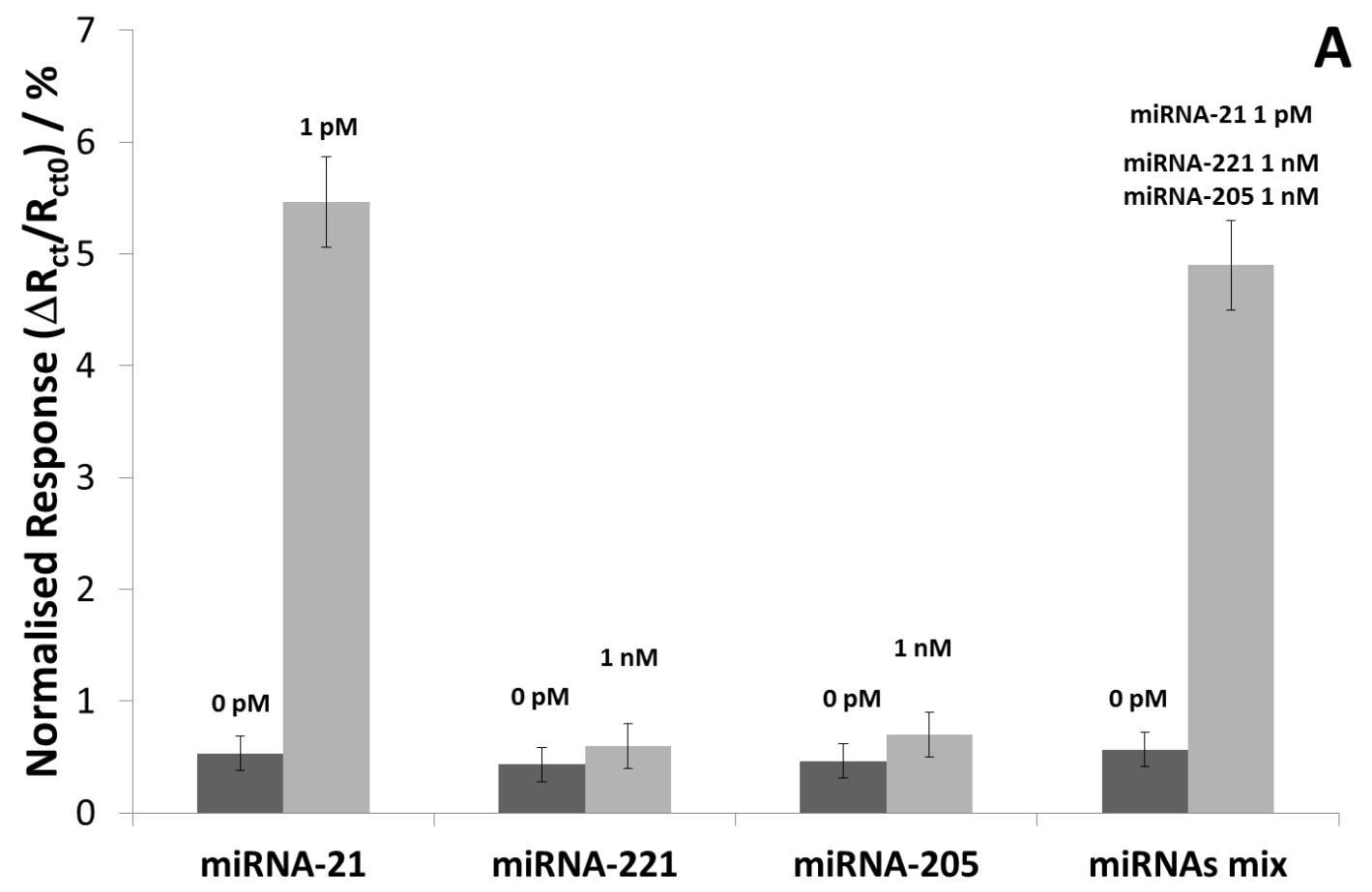

655

656

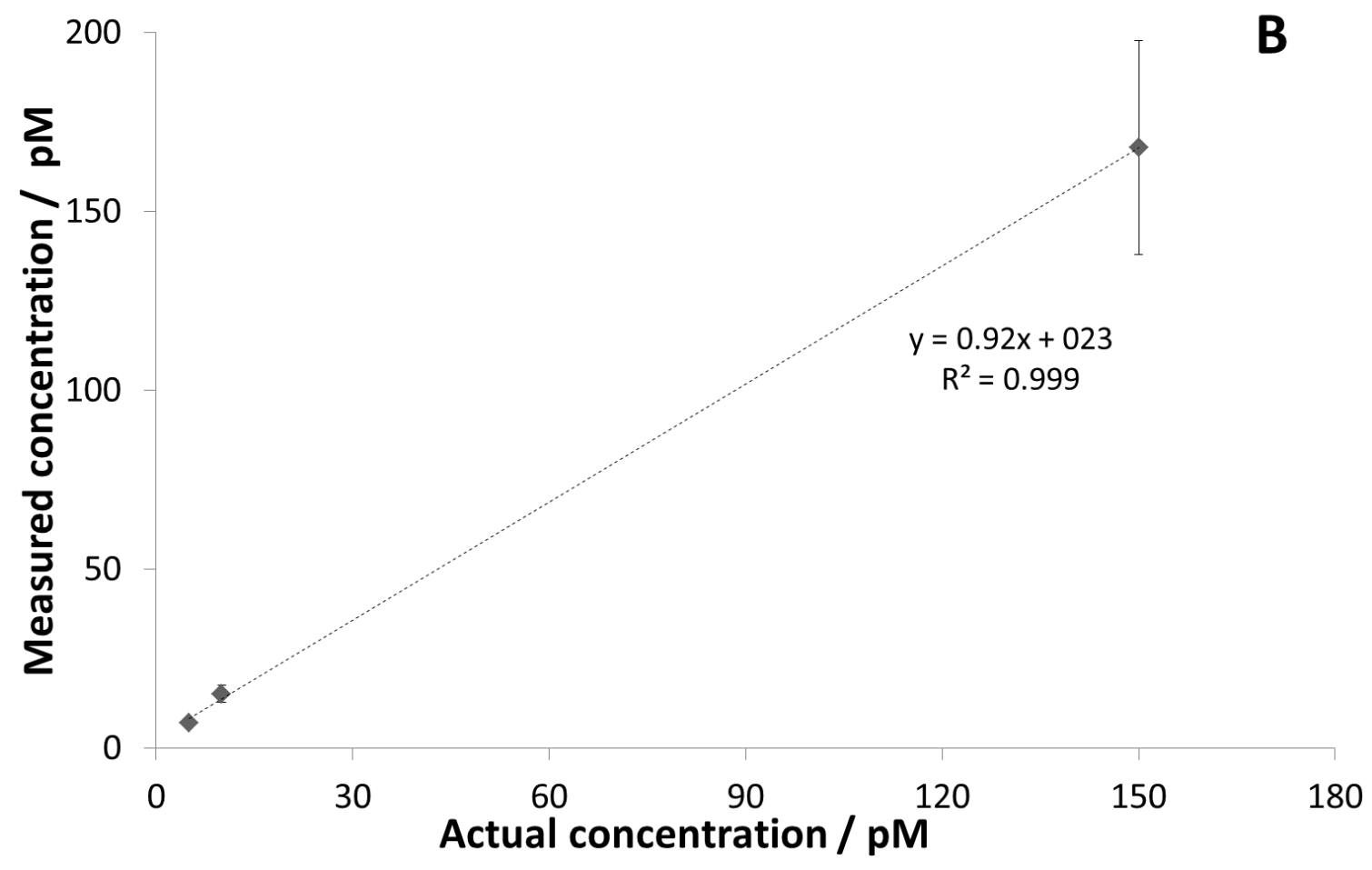

658

Figure 3 